Check for updates

Cite this: RSC Adv., 2019, 9, 19164

Received 12th April 2019

Accepted 6th June 2019

DOI: $10.1039 / c 9 r a 02766 a$

rsc.li/rsc-advances

\section{Fabrication of PP hollow fiber membrane via TIPS using environmentally friendly diluents and its $\mathrm{CO}_{2}$ degassing performance $\uparrow$}

\author{
Su-Ying Yan, ${ }^{a}$ Yu-Jie Wang, ${ }^{\text {ab }}$ Heng Mao ${ }^{b}$ and Zhi-Ping Zhao (DD *a
}

$\mathrm{CO}_{2}$ removal is an essential water purification process in many fields, such as petrochemical production and thermal power generation. It is challenging to remove low concentrations of $\mathrm{CO}_{2}$ from $\mathrm{RO}$ effluent water. The core component of the membrane degassing technique is a high-performance hydrophobic microporous membrane. Polypropylene (PP) membranes were prepared with environmentally friendly binary diluents via thermally induced phase separation. Firstly, the effects of PP concentration on the phase diagram, flat sheet membrane structure and mechanical properties were studied to optimize the PP content for a hollow fiber membrane (HFM). The PP HFM showed a sponge-like cross-sectional structure without any dense skin layer, a large loading force and breaking elongation, and a narrow pore size distribution with a mean pore size of $0.16 \mu \mathrm{m}$. The as-fabricated PP HFM module was applied for $\mathrm{CO}_{2}$ removal from $\mathrm{RO}$ effluent water from a petrochemical plant. A higher water temperature and vacuum degree facilitated $\mathrm{CO}_{2}$ removal. Increasing the effective membrane length enhanced degassing efficiency. Increasing the water flow rate increased $\mathrm{CO}_{2}$ degassing flux, but simultaneously decreased

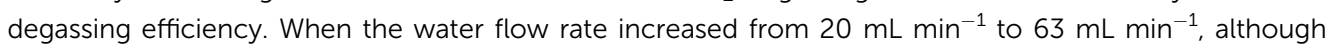
the effective membrane length increased from $3 \mathrm{~m}$ to $4.8 \mathrm{~m}$ for the best degassing efficiency of $88 \%$, the amount of treated water increased by 3.15 times. The declined $\mathrm{CO}_{2}$ concentration in the outlet water was $1.6 \mathrm{mg} \mathrm{L}^{-1}$.

\section{Introduction}

$\mathrm{CO}_{2}$ removal from water is an essential water purification process in many fields: for example, petrochemical production, thermal power generation and fabrication of microelectronic devices. ${ }^{1}$ Typically, boiler water systems in petrochemical plants require large amounts of high-quality water. ${ }^{2} \mathrm{CO}_{2}$ in the water needs to be removed before the ion exchange bed, as it adds an excessive load to the ion exchange bed, resulting in frequent chemical regeneration. ${ }^{3}$ In reverse osmosis (RO) and electrodeionization (EDI) systems, the $\mathrm{CO}_{2}$ content must also be controlled. ${ }^{4}$ In an RO system, the removal $\mathrm{CO}_{2}$ can be achieved by adding an alkali such as sodium hydroxide. However, this may lead to more chemical pollutants in RO concentrated water. ${ }^{5}$ Traditional industrial degassing technologies, including packed towers, spray towers and bubble columns, have many

${ }^{a}$ School of Chemistry and Chemical Engineering, Beijing Institute of Technology, Beijing 102488, China. E-mail: zhaozp@bit.edu.cn; Fax: +86-10-68911032; Tel: +8610-68911032

${ }^{b}$ Environmental Protection Research Institute, Beijing Research Institute of Chemical Industry, SINOPEC, Beijing 100013, China

$\dagger$ Electronic supplementary information (ESI) available: Experimental details, comparisons of mechanical properties with literature data, the other properties of fabricated PP hollow fiber membranes. See DOI: 10.1039/c9ra02766a shortcomings such as large floor areas and operational problems like entrainment, flooding, and emulsion foaming. ${ }^{6}$

A hollow fiber membrane (HFM) contactor, as a promising method for $\mathrm{CO}_{2}$ absorption and desorption, was first introduced in 1985 by Qi and Cussler.' Within this technique, a liquid phase and a gas phase can make non-dispersive contact via a microporous membrane that functions as the interface between liquid and gas. ${ }^{8,9}$ Hence, liquid flows inside HFMs, while outside the HFMs, stripping gas or a vacuum were employed. The dissolved gas leaves the liquid phase, penetrates into the membrane pores and then enters the gas phase. ${ }^{10}$

Membrane technology has unique advantages, including large interfacial area, independent control of the fluid flow rates, small size, modularity and ease of scaling up or down, as well as operational flexibility. ${ }^{11}$ Despite the fact that membrane absorption and membrane degassing are two applications for membrane contactors, most research has emphasized $\mathrm{CO}_{2}$ absorption using gas-liquid membrane contactors. Indeed, investigations into $\mathrm{CO}_{2}$ degassing through membrane contactors are very rare in the current literature. A few studies reported $\mathrm{CO}_{2}$ degassing using different HFM modules. Mansourizadeh and Ismail ${ }^{12}$ employed porous polyvinylidene fluoride (PVDF) HFMs to evaluate $\mathrm{CO}_{2}$ stripping performance from water. The results indicated that the liquid phase temperature, gas-liquid contact area and contact time are the 
key parameters for enhancing $\mathrm{CO}_{2}$ stripping efficiency. RahbariSisakht et al. ${ }^{13}$ used a polysulfone HFM contactor for $\mathrm{CO}_{2}$ stripping from water. The results showed that the gas velocity had a minor effect on the $\mathrm{CO}_{2}$ desorption flux. Khaisri et al. ${ }^{\mathbf{1 4}}$ employed polytetrafluoroethylene (PTFE) hollow fiber membranes to investigate the $\mathrm{CO}_{2}$ desorption performance from $\mathrm{CO}_{2}$-loaded monoethanolamine (MEA) solutions. The high membrane porosity showed superior desorption performance, but the long-term performance underwent severe degradation due to membrane wetting. Under high temperature conditions, Koonaphapdeelert et $a l^{15}$ used costly ceramic hollow fiber membrane contactors for $\mathrm{CO}_{2}$ stripping from MEA solution.

Since membrane fouling and wetting will reduce the degassing efficiency, there are several requirements for ideal membrane materials: ${ }^{16}$ (1) outstanding chemical and thermal stability; (2) excellent hydrophobicity; (3) high mechanical strength; (4) feasibility for commercial application. Pore size and pore size distribution also have large effects on degassing performance.

Degassing membranes are mainly produced from hydrophobic polymers, particularly polypropylene (PP), PTFE, polyethylene, and poly(vinylidene fluoride). ${ }^{17} \mathrm{PP}$ is commonly used for membrane preparation because of its excellent properties. PP membranes are usually produced by stretching or thermal methods, on account of their insolubility in common solvents. ${ }^{18}$ In fact, several papers have reported the preparation of hydrophobic microporous PP HFM via a thermally induced phase separation (TIPS) process, and membrane structure and morphology were optimized by adjusting various preparation conditions. Lloyd et al. studied the solid-liquid (S-L) and liquid-liquid (L-L) phase separation of porous PP membranes prepared via TIPS. $^{19}$ The parameters of diluent type and its content, $^{20}$ polymer concentration ${ }^{21}$ etc. could influence the compatibility between polymer and diluents, and lead to different phase separation types, which would further determine the membrane morphology, pore size and membrane performance.

Nowadays, most PP membranes prepared via TIPS use various single and binary diluents, such as diphenyl ether (DPE), ${ }^{22}$ soybean oil and dibutyl phthalate (DBP), ${ }^{23}$ etc. Binary diluents can greatly influence the compatibility between polymer and diluents, and can significantly change the phase separation behavior and membrane morphology. However, some diluents mentioned above may be toxic and harmful to human health. In previous studies, we chose castor oil (CO) and soybean oil (SO) as environmentally friendly binary diluents and optimized the appropriate binary diluents mass ratio.

As mentioned above, the studies of membrane degassing reported so far focus on absorption of high-concentration $\mathrm{CO}_{2}$ solutions. It is challenging to remove a low concentration of $\mathrm{CO}_{2}$ from RO effluent water. Herein, microporous PP HFM was prepared via TIPS for $\mathrm{CO}_{2}$ degassing from RO effluent water from a petrochemical enterprise. Firstly, the effects of PP concentration on the phase diagram, membrane structure and mechanical properties were studied during preparation of PP flat-sheet membranes in order to optimize the PP content for
HFM. PP HFM was then fabricated via TIPS with the optimal casting solution composition. Furthermore, the $\mathrm{CO}_{2}$ degassing performance of the PP membrane module was studied with RO effluent water. The effects of feed flow rate, vacuum degree, temperature, and effective membrane length on $\mathrm{CO}_{2}$ degassing performance were investigated.

\section{Experimental and materials}

\subsection{Materials}

SO and $\mathrm{CO}$ were bought from COFCO, Co. China. The PP was provided by Sinopec, F280M, MI = $2.8 \mathrm{~g} / 10 \mathrm{~min}\left(190{ }^{\circ} \mathrm{C}, 2.16\right.$ $\mathrm{kg}), M_{\mathrm{w}}=400000, M_{\mathrm{w}} / M_{\mathrm{n}}=7.7$. Sodium hydroxide was purchased from Beijing Chemical Works, China. Phenolphthalein and potassium hydrogen phthalate were purchased from Shanghai Macklin Biochemical, China. Ethanol and $n$ hexane of analytical grade were purchased from China Sinopharm Chemical Reagent Co., China.

\subsection{Phase diagram and membrane preparation}

Homogeneous PP-diluents solid samples were prepared by a previously described method. ${ }^{24}$ The sample preparation conditions are listed in detail in Table S1 (in ESI $\dagger$ ). A small piece of solid sample was sandwiched between two glass coverslips, sealed around with vacuum grease to limit evaporation of diluents. The sample was heated on a hot stage (Linkam THMS 600 , UK) up to $200{ }^{\circ} \mathrm{C}$ at a heating rate of $50{ }^{\circ} \mathrm{C} \mathrm{min}{ }^{-1}$, maintained for $5 \mathrm{~min}$ to assure homogeneity, then cooled to about $50{ }^{\circ} \mathrm{C}$ at a cooling rate of $10{ }^{\circ} \mathrm{C} \mathrm{min}^{-1}$. The cloud point temperature of the sample was determined visually by noting the appearance of turbidity under a phase contrast mode microscope (BX51M, Olympus, JAPAN). The crystallization temperature of the sample was determined visually by noting the appearance of nucleation under a polarized microscope (BX51M, Olympus, JAPAN). The temperature values were obtained based on an average of three parallel measurements.

Detail of the preparation of PP flat-sheet membranes and PP HFMs via TIPS can be found in ESI. $\dagger$

\subsection{Membrane characterization}

2.3.1. Scanning electron microscopy (SEM). The morphologies of the flat-sheet membranes and HFM were photographed on an SEM microscope (Hitachi S-4800, Japan) under an accelerating voltage of $1.0 \mathrm{kV}$. The surface and cross-section of the membrane were sputtered with $\mathrm{Au}$ in a vacuum for $50 \mathrm{~s}$.

2.3.2. Pore size and pore size distribution. The pore size and pore size distribution of the PP HFMs were measured by a fully-automatic bubble pressure method filter membrane pore size analyzer (3H-2000PB, BeiShiDe Instrument Technology Co., Ltd., China). The membrane samples consisted of three HFMs with a length of $20 \mathrm{~cm}$. Before measurement, the membranes were fully infiltrated with Porofil liquid (surface tension 16 dyn $\mathrm{cm}^{-1}$ ).

2.3.3. Mechanical properties test. The mechanical properties of the PP flat-sheet membranes and PP HFMs were measured with a universal machine (3342 Universal Material 
Testing Machine, Instron, USA). The PP flat-sheet membranes were cut into $10 \mathrm{~mm}$ wide strips and the PP HFMs were cut into lengths of about $60 \mathrm{~mm}$. The gap between clamps was $40 \mathrm{~mm}$, and the test was conducted with a strain rate of $40 \mathrm{~mm} \mathrm{~min}^{-1}$ at room temperature. The thickness of the PP flat-sheet membranes and the diameter of the PP HFMs were measured using an optical microscope (Olympus CX31, Japan). The mechanical properties were examined according to the obtained strength-strain curve. The average of three parallel results was reported.

2.3.4. Water contact angle and liquid entry pressure test. The details of testing the water contact angle (WCA) and liquid entry pressure (LEP) were shown in our previous report. ${ }^{24}$

2.3.5. Porosity determination. The porosity $(\varepsilon)$ of the membrane was determined according to a method based on density measurements. ${ }^{12}$

2.3.6. Gas permeability test. The PP HFM sample was fixed in a self-made test tube by connecting with a needle pressurized at $0.010 \mathrm{MPa}$ by a nitrogen bottle. Then, the gas flow rate for a certain period of time was measured by a soap film flowmeter connected to the test tube until the rate was stable, and the gas permeability was calculated based on the membrane area.

\section{4. $\mathrm{CO}_{2}$ degassing experiment}

A total of 10 PP HFMs were packed randomly in a polymethyl methacrylate tube with the two ends sealed by epoxy resin for fabrication into a membrane module. The specifications of the membrane module are given in Table 1.

The $\mathrm{RO}$ effluent water with dissolved $\mathrm{CO}_{2}$ flowed through the lumen side of the membrane module and a vacuum was introduced on the shell side. This effluent water was collected from the RO system at the Luoyang Petrochemical Engineering Corporation Ltd/SINOPEC. The water temperature was kept constant with a water bath and the flow rate was controlled by a peristaltic pump. The vacuum degree was adjusted by a vacuum regulating valve. A flow diagram of the experimental setup is shown in detail in Fig. S1 (in ESI $\dagger$ ). The $\mathrm{CO}_{2}$ concentrations of the entry and outlet water of the module were measured by the chemical titration method. ${ }^{13}$

The $\mathrm{CO}_{2}$ degassing efficiency was calculated as:

$$
\eta(\%)=\left(1-\frac{C_{\mathrm{o}, 1}}{C_{\mathrm{i}, 1}}\right) \times 100 \%
$$

where $C_{\mathrm{o}, 1}$ and $C_{\mathrm{i}, 1}$ are the liquid phase $\mathrm{CO}_{2}$ concentrations (mg $\mathrm{L}^{-1}$ ) in the outlet and inlet of the membrane contactor, respectively.

Table 1 Specifications of the PP HFM module

\begin{tabular}{ll}
\hline Properties & Values \\
\hline Length of module/ & 70 \\
$\mathrm{~cm}$ & \\
Effective length/cm & 60 \\
Module I.D/O.D/cm & $4.3 / 5.0$ \\
Fiber I.D/O.D/ $\mu \mathrm{m}$ & $1161 / 1822$ \\
No. of fibers & 10
\end{tabular}

The $\mathrm{CO}_{2}$ degassing flux was calculated as:

$$
J_{\mathrm{CO}_{2}}=\frac{\left(C_{\mathrm{i}, 1}-C_{\mathrm{o}, 1}\right) \times Q_{1}}{A_{\mathrm{i}}}
$$

where $J_{\mathrm{CO}_{2}}$ is the $\mathrm{CO}_{2}$ degassing flux $\left(\mathrm{mol} \mathrm{m}^{-2} \mathrm{~s}^{-1}\right) ; Q_{1}$ is the feed flow rate $\left(\mathrm{m}^{3} \mathrm{~s}^{-1}\right)$; and $A_{\mathrm{i}}$ is the inner surface area of the PP HFMs $\left(\mathrm{m}^{2}\right)$.

\section{Results and discussion}

\subsection{Phase diagram}

The type of phase separation is directly determined from the phase diagram..$^{20,25}$ Fig. 1 is the phase diagram of the PP/binary diluents system on various PP concentrations with $16 \mathrm{wt} \% \mathrm{CO}$ in the diluents. It presents cloud point and dynamic crystallization temperatures. The cloud point decreased greatly with an increase in PP concentration. The cloud point reached its highest value of $176{ }^{\circ} \mathrm{C}$ at $10 \mathrm{wt} \% \mathrm{PP}$, and dropped to $136^{\circ} \mathrm{C}$ at $40 \mathrm{wt} \% \mathrm{PP}$. The phenomena can be analysed in terms of the interaction between PP and the binary diluents. The FloryHuggins interaction parameter $(\chi)$ is typically used to interpret the interaction between the polymer and the diluent. When the PP concentration was increased, the $\chi$ became smaller, which resulted in the decrease in cloud point. ${ }^{20}$ This indicated that when the PP concentration ranged from $10 \mathrm{wt} \%$ to $40 \mathrm{wt} \%$, the $\mathrm{PP} /$ binary diluents system showed a typical L-L phase separation. However, a high viscosity of casting solution is unfavorable for membrane preparation due to the high PP concentration. Thus, the PP content was controlled at $40 \mathrm{wt} \%$.

Moreover, Fig. 1 shows that the crystallization temperature of PP remains almost constant within the range of PP concentrations studied, which is characteristic of the crystal phase formed in $\mathrm{L}-\mathrm{L}$ phase separation and is consistent with the results reported previously. ${ }^{20}$ The crystallization temperature of the original PP in this study was about $127^{\circ} \mathrm{C}$, the addition of binary diluents contributed to this slight decrease.

\subsection{Effect of PP concentration on the flat-sheet membrane properties}

3.2.1. Membrane morphology. The effect of PP content on membrane morphology was investigated by fixing a binary

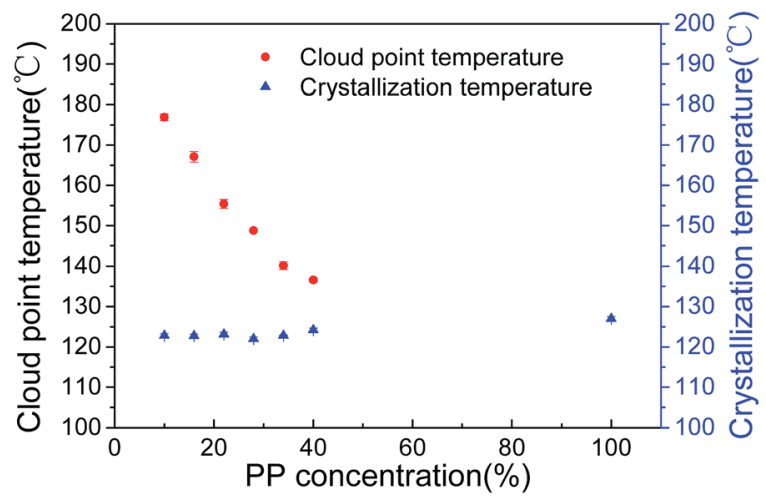

Fig. 1 Phase diagram for the PP/binary diluents system with various PP contents: diluents content (SO/CO): 84/16. 
diluents containing $16 \mathrm{wt} \% \mathrm{CO}$. The surface and cross-sectional morphologies of the membranes were observed by SEM. As shown in Fig. 2, the cross-section of the flat-sheet membranes with different PP concentrations remains an interconnected sponge-like structure, which confirms the occurrence of L-L phase separation. Moreover, the cross-sectional structure becomes highly compact, and the pores are almost closed when the PP concentrations are $34 \mathrm{wt} \%$ and $40 \mathrm{wt} \%$. The surface of all the flat-sheet membranes shows a non-porous structure due to the insolubility between the casting solution and the water coagulation bath. On the other hand, the fast solidification caused by rapid cooling when the homogeneous casting solution was quenched from $195{ }^{\circ} \mathrm{C}$ to the $15^{\circ} \mathrm{C}$ also caused a dense surface. $^{26}$

The SEM images also show that the pore size of the flat-sheet membranes decreased slightly with an increase in PP concentration. Phase separation was induced by lowering the temperature in the TIPS process. The PP phase formed the membrane skeleton and the diluent phase became the membrane pores upon diluent extraction. Therefore, the increase in PP concentration decreased membrane pore size. ${ }^{27}$ On the other hand, during the L-L phase separation process, when the PP concentration increased, the $\mathrm{L}-\mathrm{L}$ phase separation region became smaller, and then the lean-polymer phase grew for a shorter time, so the pore size decreased. ${ }^{19}$

3.2.2. Mechanical properties. Fig. 3 shows the mechanical properties of PP flat-sheet membranes with different PP concentrations. The results indicated that the loading force became higher with PP concentration. The breaking elongation also increased with PP concentration, but when the PP
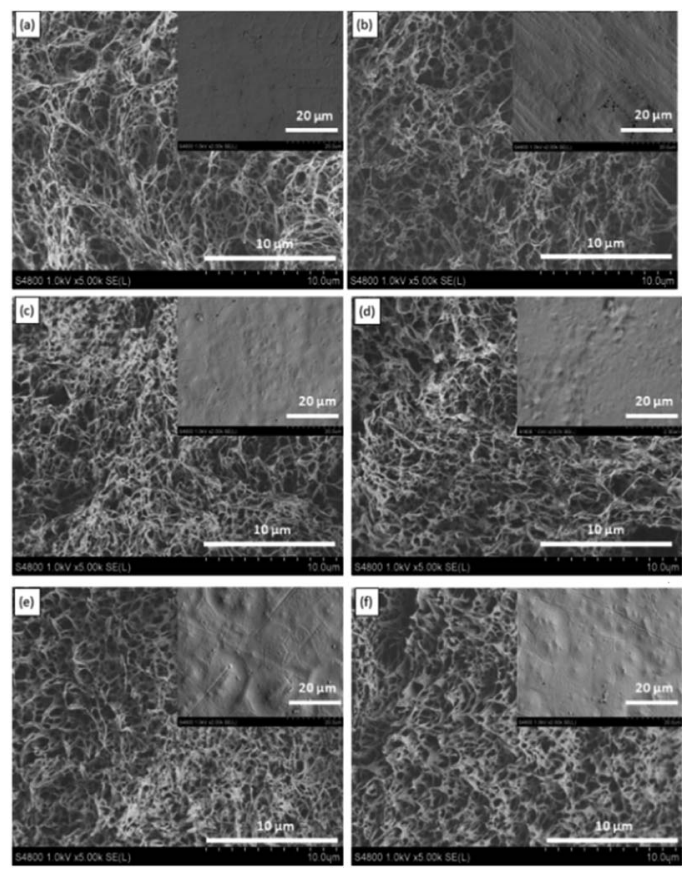

Fig. 2 SEM images of PP flat-sheet membranes using various PP concentrations. (PP concentration: (a) 10 wt\%; (b) 16 wt\%; (c) 22 wt\%; (d) 28 wt\%; (e) 34 wt\%; (f) 40 wt\%. Cross-section at magnification 5k and inserts showing the surface at magnification $2 \mathrm{k}$ ).

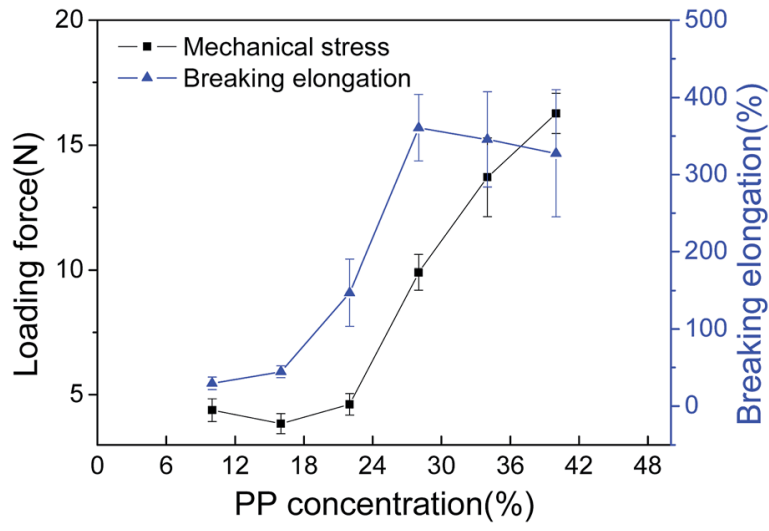

Fig. 3 Mechanical properties of PP membranes prepared with different PP concentrations.

concentration increased to $40 \mathrm{wt} \%$, the breaking elongation decreased slightly. It was observed that the membranes prepared with more than $28 \mathrm{wt} \%$ PP became both crispy and hard, and, as also shown in Fig. 2, the pores in cross-section became compact, which resulted in the decline in breaking elongation. A similar phenomenon was also found in our previous study, where PP flat-sheet membranes were prepared using carnauba wax and SO as binary diluents. ${ }^{24}$

The results in Fig. 1 indicated that the $\mathrm{PP} / \mathrm{SO} / \mathrm{CO}$ systems with PP concentrations ranging from $10 \mathrm{wt} \%$ to $40 \mathrm{wt} \%$ all underwent $\mathrm{L}-\mathrm{L}$ phase separation. If the PP concentration was higher than $28 \mathrm{wt} \%$, it was difficult to scrape the membranes due to the high viscosity of the casting solution. On the other hand, when the PP concentration was less than $20 \mathrm{wt} \%$, the loading force of the resulting membranes was poor. In addition, the pore size of the membranes decreased with increasing PP concentration. Furthermore, the relatively small pore size was favorable for resistance to water penetration. Therefore, considering the smaller pore size and high mechanical properties, $28 \mathrm{wt} \%$ PP was appropriate for this PP/diluents system.

\subsection{Characterizations of PP HFM}

3.3.1. Membrane morphology. Based on the effects of PP concentration on the phase diagram, loading force and breaking elongation of flat-sheet membrane, the selected compositions were $28 \mathrm{wt} \% \mathrm{PP}$ with a mass ratio CO/SO of $16 / 84$. Fig. 4 shows the structure of the outer surface, inner surface and cross-sectional structure of PP HFM. Prepared at a relatively slow cooling rate, the membrane showed discernable spherulites in its overall look, indicating that L-L phase separation mainly occurred. However, the membrane structure in the interspherulitic space and intra-spherulitic space showed an interconnected sponge-like structure.

As also shown in Fig. 4, the inner and outer surfaces have no dense skin layer but a loose porous morphology. In PP HFM preparation, diluent-like solvents with a 90/10 mass ratio of $\mathrm{SO} /$ CO were applied in both the bore liquid and the outer coagulation baths. The diluent-like solvents had good compatibility with the binary diluents, and could exchange with the casting 

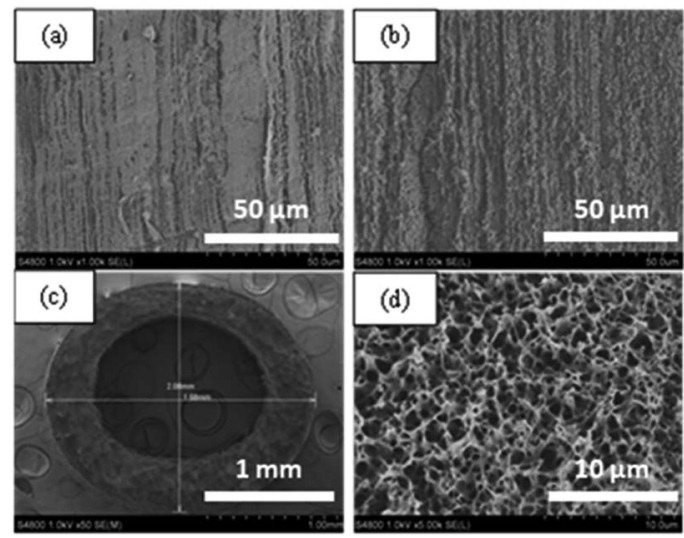

Fig. 4 SEM images of PP HFM: (a) inner surface; (b) outer surface; (c) cross-section with magnification 50; (d) cross-section with magnification $5 \mathrm{k}$.

solution on the inner and outer surfaces to result in a porous structure. ${ }^{26}$

3.3.2. Mechanical properties. Fig. 5 shows the strengthstrain curves for three parallel tests of PP HFMs. According to the strength-strain curve analyses of the PP HFMs during the measurements, the instrument automatically calculated a loading force of $6.78 \pm 0.23 \mathrm{~N}$, a tensile strength of $4.38 \pm$ $0.15 \mathrm{MPa}$, a Young's modulus of $123.7 \pm 19.7 \mathrm{MPa}$ and a breaking elongation of $27.87 \pm 3.9 \%$. It should be noticed that the breaking elongation of HFM was weaker than that of the flat-sheet membrane with the same composition of casting solution, which was mainly due to the relatively slow cooling rate. The PP HFM has excellent breaking elongation and strength. A comparison of the mechanical properties with the literature data is shown in Table S2 (in ESI $\dagger$ ).

3.3.3. Pore size and pore size distribution. The pore size and pore size distribution of the PP HFMs prepared with $16 \mathrm{wt} \%$ CO in the diluents are shown in Fig. 6 . The results indicate that the PP HFMs presented a narrow and uniform pore size distribution with a mean pore size of $0.16 \mu \mathrm{m}$.

This narrow pore size structure is helpful for preventing the membrane pore from being wetted and penetrated by water, for a long-term stable performance.

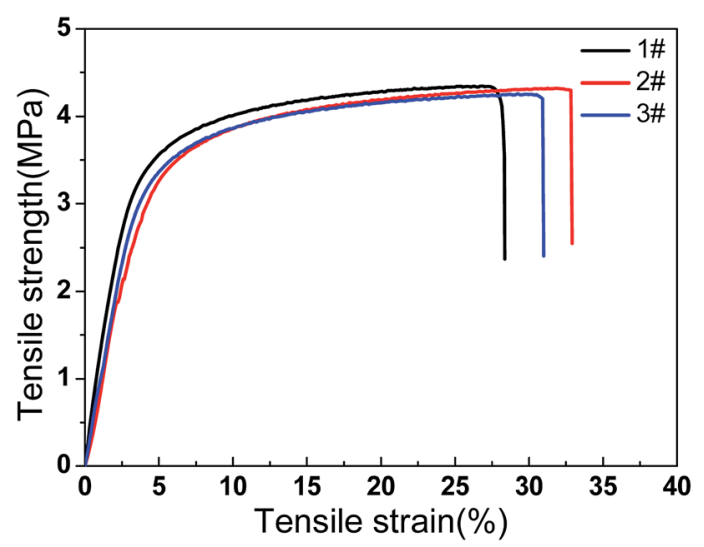

Fig. 5 Strength versus strain curves of three parallel tests of PP HFMs.

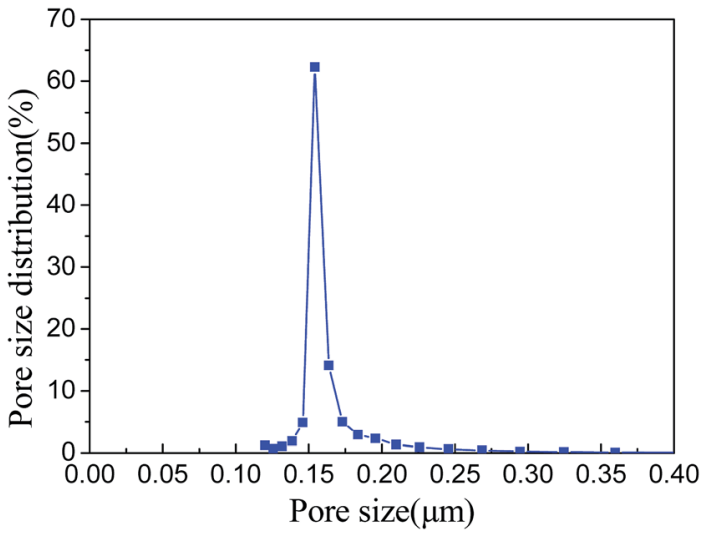

Fig. 6 Pore size and pore size distribution of PP HFM.

The other properties of PP HFM, including water contact angle (WCA), liquid entering pressure (LEP), etc. are summarized in Table S3 (ESI $\dagger$ ).

\subsection{Effects of operational parameters on degassing performance}

3.4.1. Feed flow rate. The $\mathrm{CO}_{2}$ concentration of the employed RO effluent water was $12.56 \mathrm{mg} \mathrm{L}^{-1}$. As shown in Fig. 7(a), the degassing efficiency decreased gradually with an increase in water flow rate. The largest $\mathrm{CO}_{2}$ degassing efficiency was $57.4 \%$ when the flow rate was $20 \mathrm{~mL} \mathrm{~min}^{-1}$. Although the reduced liquid phase boundary thickness enhanced the mass transfer when the flow rate increased, the residence time of water in the membrane decreased sharply. This result demonstrated that the gas-liquid contact time played an important role in $\mathrm{CO}_{2}$ degassing. Therefore, a higher degassing efficiency should be achieved at a longer residence time.

However, the degassing flux increased gradually with water flow rate, indicating that the increase in flux was mainly caused by increasing flow rate, although the $\mathrm{CO}_{2}$ concentration change was smaller. ${ }^{28}$ Hence, in terms of $\mathrm{CO}_{2}$ degassing flux, a higher flow rate was considered to be better. At a higher water flow rate, the mass transfer resistance of the liquid phase became smaller, but the operating energy consumption might increase. However, the flow state was still in the laminar flow region (Reynolds number 126) at a flow rate of $63 \mathrm{~mL} \mathrm{~min}^{-1}$. This is acceptable considering the fluid resistance energy consumption.

3.4.2. Vacuum degree. Fig. 7(b) shows that the degassing efficiency and degassing flux both increased slightly when the vacuum degree increased, mainly due to the enhancement in mass transfer driving force. When the vacuum degree increased, the mass transfer driving force apparently became larger.

3.4.3. Feed water temperature. As shown in Fig. 7(c), the degassing efficiency increased slightly within a narrower elevated temperature range. This result could be attributed to the influence of two variables: solubility and diffusion coefficient. The $\mathrm{CO}_{2}$ solubility decreased in water with an elevated temperature. Moreover, the $\mathrm{CO}_{2}$ diffusion coefficient 

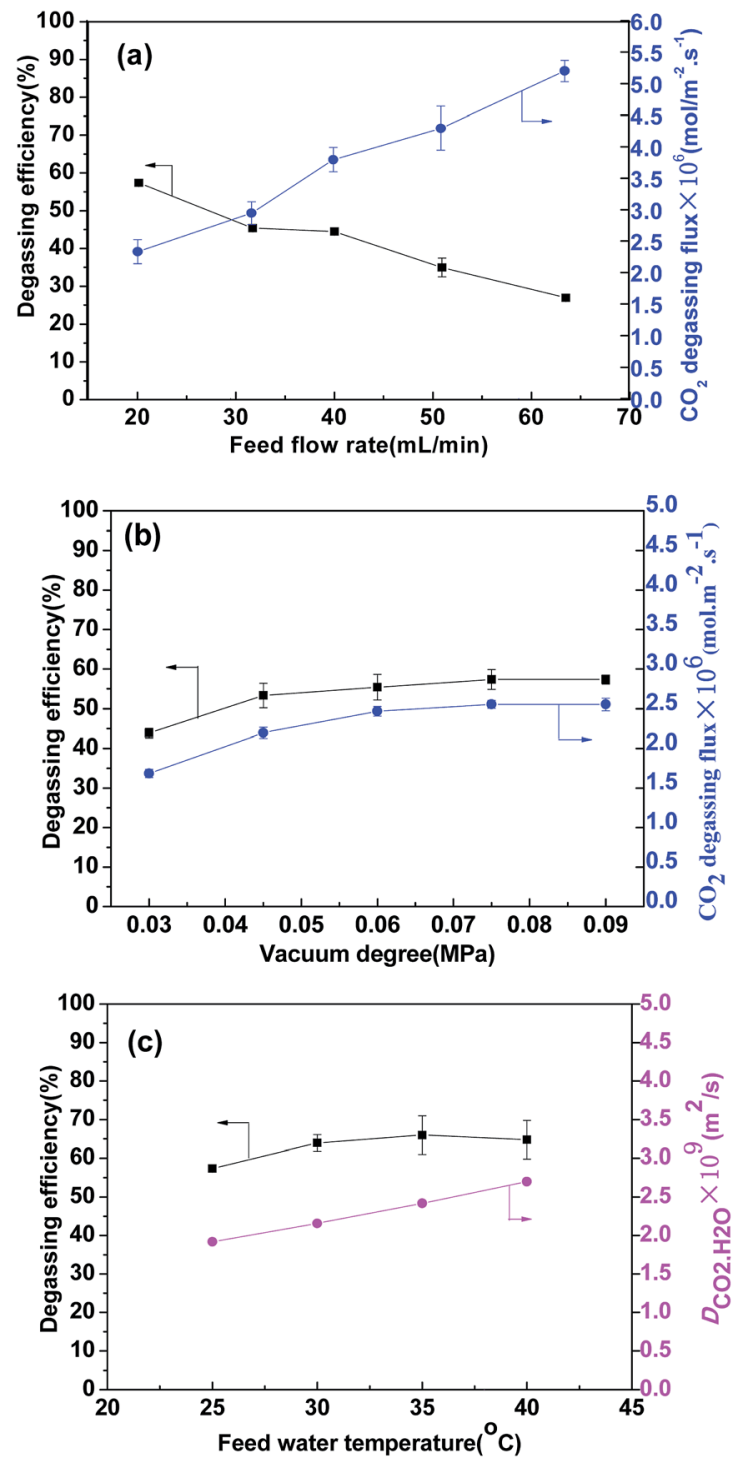

Fig. 7 Effects of operational parameters on degassing performance. (a) Feed flow rate; (b) vacuum degree; (c) feed water temperature. (Operating conditions: (a) water temperature of $298 \mathrm{~K}$; vacuum degree of $0.095 \mathrm{MPa}$. (b) water temperature of $298 \mathrm{~K}$; flow rate of $20 \mathrm{~mL} \mathrm{~min}{ }^{-1}$ (c) $\mathrm{CO}_{2}$ concentration of $16.5 \mathrm{mg} \mathrm{L}^{-1}$; vacuum degree of $0.095 \mathrm{MPa}$;

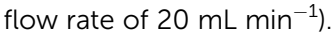

increased. ${ }^{29}$ These changes led to the improvement in degassing performance. However, after $30^{\circ} \mathrm{C}$, the degassing performance was basically stable.

3.4.4. Effective membrane length. In order to enhance the degassing efficiency, one efficient approach is to increase the effective membrane length, thereby prolonging the water retention time in the membrane. Generally, the membrane modules could be connected in series. However, due to restrictions on the number of modules, this experiment was carried out by increasing the operating circle times. Herein, one degassing operation means that the effective membrane length is $0.6 \mathrm{~m}$; for two operations the effective membrane length is 1.2 $\mathrm{m}$, and so on.

The effect of effective membrane length under two flow rates was investigated and the results are presented in Fig. 8. In
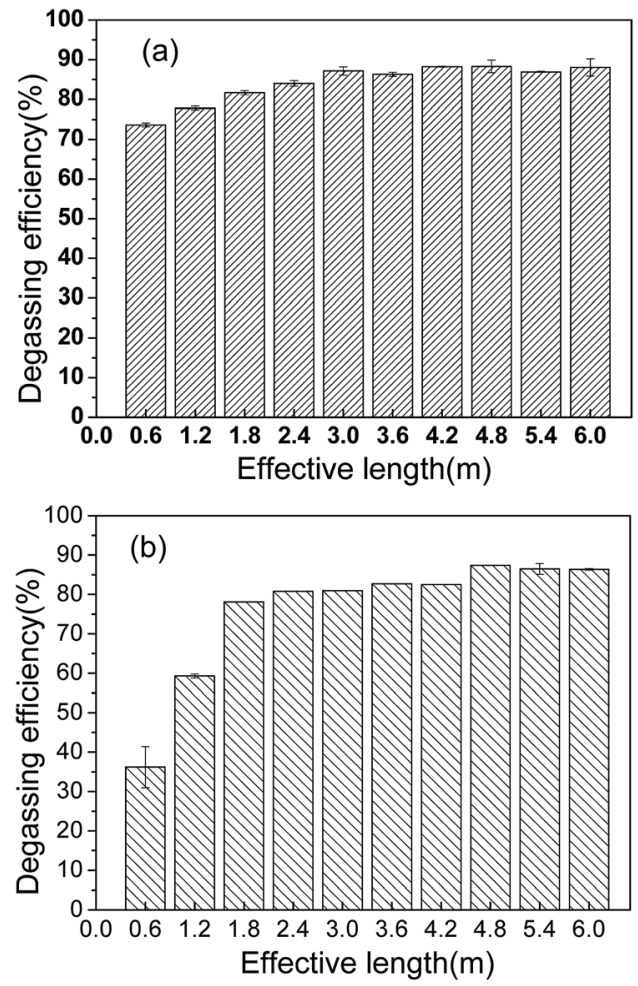

Fig. 8 Effect of effective length on degassing efficiency. (Operating conditions: initial $\mathrm{CO}_{2}$ concentration of $16.5 \mathrm{mg} \mathrm{L}^{-1}$; vacuum degree

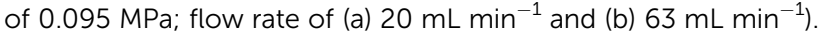

Fig. 8(a), when the effective length increased from $0.6 \mathrm{~m}$ to $3 \mathrm{~m}$, the $\mathrm{CO}_{2}$ removal efficiency increased. When the length reached $3 \mathrm{~m}$, it was basically stable at about $88 \%$, and the $\mathrm{CO}_{2}$ content of the outlet water declined to $1.6 \mathrm{mg} \mathrm{L}^{-1}$. From Fig. 8(b) for 63 $\mathrm{mL} \mathrm{min}^{-1}$, the degassing efficiency of the first circle got smaller. But it increased rapidly in the next two circles. After that, the increase trend slowed down. The final degassing efficiency reached about $87 \%$ at $4.8 \mathrm{~m}$. The Reynolds number in the fiber lumen increased from 40 to 126 when the flow rate varied from $20 \mathrm{~mL} \mathrm{~min}^{-1}$ to $63 \mathrm{~mL} \mathrm{~min}^{-1}$. The mass transfer at a higher flow rate was enhanced. It was concluded that the degassing performance could be improved with a longer membrane length or at a higher flow rate. For a single membrane module, it seems that only when the membrane is long enough can a desired degassing efficiency be achieved. For a large processing capacity in industrial applications, a higher water flow rate was considered to be better. As for the $\mathrm{CO}_{2}$ removal efficiency, it can be ensured by increasing operation circle times or connecting the modules in series.

\section{Conclusions}

Hydrophobic PP HFMs prepared via TIPS with environmentally friendly binary diluents were fabricated into a membrane contactor for $\mathrm{CO}_{2}$ degassing from RO effluent water from petrochemical production. The following conclusions were drawn:

(1) The phase diagram indicated that the cloud point temperature decreased with PP concentrations from $10 \mathrm{wt} \%$ to $40 \mathrm{wt} \%$, but the crystallization temperature was almost stable. 
The cross-sections of the PP flat-sheet membranes displayed a sponge-like structure. The largest breaking elongation was achieved at $28 \mathrm{wt} \% \mathrm{PP}$.

(2) PP HFM showed a sponge-like cross-sectional structure without any dense skin layer, a large loading force and breaking elongation, and a narrow pore size distribution with a mean pore size of $0.16 \mu \mathrm{m}$.

(3) When the flow rate increased from $20 \mathrm{~mL} \mathrm{~min}^{-1}$ to 63 $\mathrm{mL} \min ^{-1}$, the effective membrane length increased from $3 \mathrm{~m}$ to $4.8 \mathrm{~m}$ for the best degassing efficiency of about $88 \%$; the amount of treated water or $\mathrm{CO}_{2}$ removed increased by 3.15 times.

\section{Conflicts of interest}

There are no conflicts to declare.

\section{Acknowledgements}

This study was supported by the National Natural Science Foundation of China (No. 21576024) and the project fund under Grant no. 15-16ZS0522 from the Beijing Research Institute of Chemical Industry, SINOPEC.

\section{References}

1 K. Li, I. Chua, N. J. Ng and W. K. Teo, Chem. Eng. Sci., 1995, 50, 3547-3556.

2 Z. G. Peng, S. H. Lee, T. Zhou, J. J. Shieh and T. S. Chung, Desalination, 2008, 234, 316-322.

3 M. Bassandeh, A. Antony, L. C. Pierre, D. Richardson and G. Leslie, Chemosphere, 2013, 90, 1461-1469.

4 Ö. Arar, Ü. Yüksel, N. Kabay and M. Yüksel, Desalination, 2014, 342, 16-22.

5 M. Raffin, E. Germain and S. Judd, Desalin. Water Treat., 2012, 40, 302-308.

6 E. Drioli, E. Curcio and G. Di Profio, Chem. Eng. Res. Des., 2005, 83, 223-233.

7 Q. Zhang and E. L. Cussler, J. Membr. Sci., 1985, 23, 321-332. 8 E. Kianfar, V. Pirouzfar and H. Sakhaeinia, J. Taiwan Inst. Chem. Eng., 2017, 80, 954-962.

9 S. Hosseini and A. Mansourizadeh, J. Taiwan Inst. Chem. Eng., 2017, 76, 156-166.
10 M. X. Fang, Z. Wang, S. P. Yan, Q. G. Cen and Z. Y. Luo, Int. J. Greenhouse Gas Control, 2012, 9, 507-521.

11 M. Henares, M. Izquierdo, J. M. Penya-Roja and V. MartinezSoria, Sep. Purif. Technol., 2016, 170, 22-29.

12 A. Mansourizadeh and A. F. Ismail, Desalination, 2011, 386, 386-390.

13 M. Rahbari-Sisakht, A. F. Ismail, D. Rana, T. Matsuura and D. Emadzadeh, Sep. Purif. Technol., 2013, 108, 119-123.

14 S. Khaisri, D. deMontigny, P. Tontiwachwuthikul and R. Jiraratananon, J. Membr. Sci., 2011, 376, 110-118.

15 S. Koonaphapdeelert, Z. Wu and K. Li, Chem. Eng. Sci., 2009, 64, 1-8.

16 T. Li and T. C. Keener, Int. J. Greenhouse Gas Control, 2016, 51, 290-304.

17 S. Rajabzadeh, T. Maruyama, T. Sotani and H. Matsuyama, Sep. Purif. Technol., 2008, 63, 415-423.

18 S. Atchariyawut, C. Feng, R. Wang, R. Jiraratananon and D. T. Liang, J. Membr. Sci., 2006, 285, 272-281.

19 D. R. Lloyd, S. S. Kim and K. E. Kinzerb, J. Membr. Sci., 1991, 64, 1-11.

20 B. Zhou, Y. Tang, Q. Li, Y. Lin, M. Yu, Y. Xiong and X. Wang, J. Appl. Polym. Sci., 2015, 132, 42490.

21 N. Tang, Q. Jia, H. Zhang, J. Li and S. Cao, Desalination, 2010, 256, 27-36.

22 W. Yave, R. Quijada, D. Serafini and D. R. Lloyd, J. Membr. Sci., 2005, 263, 146-153.

23 G. Chen, Y. K. Lin and X. L. Wang, J. Appl. Polym. Sci., 2007, 105, 2000-2007.

24 Y. J. Wang, Z. P. Zhao, Z. Y. Xi and S. Y. Yan, J. Membr. Sci., 2018, 548, 332-344.

25 D. R. Lloyd, J. Membr. Sci., 1989, 52, 239-261.

26 G. L. Ji, L. P. Zhu, B. K. Zhu, C. F. Zhang and Y. Y. Xu, J. Membr. Sci., 2008, 319, 264-270.

27 Z. Cui, N. T. Hassankiadeh, S. Y. Lee, K. T. Woo, J. M. Lee, A. Sanguineti, V. Arcella, Y. M. Lee and E. Drioli, J. Membr. Sci., 2015, 473, 128-136.

28 N. A. Rahim, N. Ghasem and M. Al-Marzouqi, J. Nat. Gas Sci. Eng., 2014, 21, 886-893.

29 H. Kreulen, C. A. Smolders, G. F. Versteeg and W. P. M. Van Swaaij, Chem. Eng. Sci., 1993, 48, 2093-2102. 